\title{
Does Increased State Pharmacy Regulatory Burden Lead to Better Public Safety Outcomes?
}

\author{
Alex J. Adams, PharmD, $M P H^{1}$; Jennifer Adams, PharmD, EdD ${ }^{2}$
}

${ }^{1}$ Administrator, Idaho Division of Financial Management; ${ }^{2}$ Associate Dean for Academic Affairs, Idaho State University

\begin{abstract}
Pharmacy has traditionally been a highly regulated profession. In a recent study, the state with the largest pharmacy regulatory word count had 6.7 times as many words as the state with the lowest word count. Given the wide variation in state pharmacy regulations, this paper seeks to spark discussion on how we can assess public safety outcomes in states based on the overall volume of pharmacy regulation with a focus on: 1) fitness to practice; 2) controlled substance outcomes; and 3) compounding safety. In examining these categories, existing data sources are limited and suboptimal, though formal disciplinary actions against pharmacy licensees are very infrequent. Thus, it seems preferable for states to have a regulatory framework that allows boards of pharmacy to deal with the rare public safety issues that occur, while not holding back the vast majority of pharmacists from practicing to the top of their education and training.
\end{abstract}

Pharmacy has traditionally been a highly regulated profession. ${ }^{1}$ A benchmark report on the pharmacy, nursing, and medical statutes and regulations in Idaho found that pharmacy regulations had a higher overall word count, more overall restrictions, and had to be amended more frequently to keep pace with changing education, technology, and practice models. ${ }^{2}$

A comparison of 10 western states' pharmacy regulations found wide variation across state lines in overall regulatory burden (average of 65,882 words, SD $=35,057) .^{3}$ The state with the largest word count had 6.7 times as many words as the state with the lowest word count. Assuming an average of 500 words per page, this means states ranged from 38 to 253 pages of pharmacy regulations.

Regulations ostensibly exist to protect the public. Therefore, a common perception is that increased regulation (and thus, increased word or page count) also increases public safety. Does the state with the most pharmacy regulations enjoy 6.7 times the public protection as the state with the lowest? Put another way, do the 215 extra pages of pharmacy regulations in the most regulated state have quantifiable public protection benefits above less regulated states, or do they exist to simply add clutter or address merely the perception of protection? Might unnecessary regulations hold back services or business models that could otherwise improve public safety?

Given the wide variation in state pharmacy regulations, this paper seeks to spark discussion on how we can assess public safety outcomes in states based on the overall volume of pharmacy regulation.

Corresponding author: Alex J. Adams, PharmD, MPH Administrator, Idaho Division of Financial Management Email: alexadamsrph@gmail.com
How Can We Measure Public Safety Outcomes of Pharmacy Regulation?

Despite more than 100 years of state-based pharmacy regulation in the United States, there are not seemingly convenient ways to assess the patient safety outcomes of pharmacy regulations at the state level. There are at least three potential categories to explore suitable dependent variables that can be attributed at least in part to regulation: 1 ) fitness to practice; 2) controlled substance outcomes; and 3) compounding safety. In examining these categories, existing data sources are limited and suboptimal.

\section{A. Fitness to Practice}

A major role of regulatory boards is to ensure the fitness to practice of its licensees. When pharmacists violate state laws or fall short of practice standards, boards of pharmacy may pursue disciplinary action such as license suspension, revocation, or practice restrictions. State regulations attempt to prevent unqualified practitioners from entering into practice, ensure practitioners maintain competence over time, and attempt to prevent behaviors that may result in patient harm. Thus, the volume of disciplinary action may serve as a proxy for lack of fitness to practice, and therefore, public safety.

The National Association of Boards of Pharmacy (NABP) used to publish annual data reported by state boards of pharmacy on discipline, with separate data for suspended and revoked licenses. ${ }^{4}$ It did not include information on the reasons for disciplinary action in these summary reports and in the 2018 edition, many states either did not provide data or did not update their previous year's data. Thus, the use was limited and reporting appears to have been eliminated from more recent annual surveys. ${ }^{5}$ In 2018, the aggregate number of revocations and suspensions per state was low. Supposing all revocations and suspensions are attributed to in-state pharmacist and technician licenses alone in the states that reported new data, the state-reported rate of these actions was just $0.04 \%$ of licenses. ${ }^{4}$ 
NABP also publishes aggregate data on disciplinary actions reported by state boards of pharmacy, though no state data appears to be readily available. In 2019, 4,983 individual and organizations had discipline reported, which translates into a discipline rate of approximately $0.47 \%$ of pharmacist, pharmacy technician, and pharmacy licenses. ${ }^{6}$ These disciplinary actions include revocations and suspensions, but also includes the more frequently occurring fines, reprimands, and probation, among other less stringent actions. Reported disciplinary actions ranged from serious (e.g., drug diversion) to technical (e.g., continuing education non-compliance).

The National Practitioner Data Bank (NPDB) provides a webbased repository of reports related to healthcare providers. ${ }^{7-8}$ Federal law requires certain entities to report adverse actions and medical malpractice payouts to the NPDB, including state licensing boards, federal agencies, medical malpractice payers, and private accreditation organizations, among others. Researchers may use NPDB online Data Analysis Tool ${ }^{7}$ to generate state-level data from 1990 onward for pharmacists on the following measures:

a) Adverse Action Reports, which includes actions taken against pharmacists such as license revocation, suspension, restrictions on practice, and administrative fines, among other actions. These actions may stem from causes as diverse as continuing education violations to diversion of controlled substances and include private (e.g., clinical privileges), state, and federal (e.g., DEA and HHS) issues.

b) Medical Malpractice Payment Reports, which includes "a monetary exchange as a result of a settlement or judgment of a written complaint or claim demanding payment based on a [pharmacist's] provision of or failure to provide health care services."

For each of these NPDB measures, the average number of total adverse actions and malpractice payment reports for pharmacists, as measured by average annual number from 2010 to 2019 divided by the number of reported in-state pharmacists nationally, is low. The number of pharmacist licensees with an adverse action was just $0.55 \%$, which is close to the disciplinary action rate reported above for NABP $(0.47 \%)$. Malpractice payment reports were even rarer for pharmacists, representing just $0.01 \%$ of licensees.

Some will note that the low rate of formal discipline may stem from differences in disciplinary approaches by regulatory boards. For example, some states pursue reportable NPDB discipline for minor medication errors, whereas other states resolve similar cases through non-disciplinary means such as corrective action plans. ${ }^{9}$ This is in line with the push to treat medication errors as a system issue rather than an individual failure. ${ }^{10}$ Further, there is also some randomness to which complainants generate complaints to regulatory boards or result in civil cases. ${ }^{11}$

Conceivably, fitness to practice could also be measured by positive medication outcomes achieved, not just adverse disciplinary actions. Not surprisingly, limited data exists in this area as well. The CMS Star Ratings for medication adherence and clinical gaps in care are potential options, though data is reported only at the health plan level, not by state. ${ }^{12}$

\section{A. Controlled Substance Outcomes}

Boards of pharmacy have a large role to play in combatting the opioid use epidemic. States have implemented many restrictions above federal law intending to control opioids, including enhanced inventory requirements, prescription and dispensing limits, and mandates to use Prescription Drug Monitoring Programs (PDMPs), among other state laws. Conceivably these laws - which focus on both individual pharmacists and facility standards -- could lead to improved controlled substance outcomes.

There are several potential data sources that could be leveraged, including:

a) The Center for Disease Control and Prevention's (CDC) U.S. Opioid Prescribing Rate Map which looks at the retail opioid prescriptions dispensed per 100 persons per year; ${ }^{13}$

b) Analysis of the U.S. Drug Enforcement Agency's (DEA) Automation of Reports and Consolidated Orders System (ARCOS), which reported the grams of opioid analgesics per 100,000 individuals in the state; ${ }^{14}$ and

c) The CDC's age-adjusted rates of drug overdose by state, which includes all drugs, though opioids account for $66.4 \%$ of all drug overdose deaths. ${ }^{15}$

Many states also have laws regarding facility standards and security for pharmacies which generally aim to prevent robberies and diversion of controlled substances. Given this, we could leverage state-level data provided by the DEA on federal burglary and armed robbery reports from retail pharmacies of controlled substances by calendar year. ${ }^{16-17}$ These can be converted into per capita rates if divided by the total number of pharmacies reported in the state. ${ }^{18}$

\section{B. Compounding Safety}

Poor compounding practices caused one of the most significant public health crises in the modern pharmacy profession. ${ }^{19}$ Boards of pharmacy, along with the FDA, are major regulators of compounding, and thus compounding safety outcomes are likely of great interest.

Compounding actions taken by the U.S. Food and Drug Administration (FDA) are reported on their public webpage for inspections, recalls, and other actions. ${ }^{20}$ Researchers can extract state-level data by counting the number of warning 
letters, Form 483 issuance (letters issued to a firm "at the conclusion of an inspection when an investigator observed any conditions that...may constitute violations of [law]"), referral letters, state handoff letters, and compounding risk alerts issued against pharmacies in the relevant states. The number of aggregate FDA actions can be divided by the total number of pharmacies in the state to calculate an aggregate per capita rate. Of course, FDA actions reflect those taken by a federal agency, but state boards of pharmacy often collaborate with the FDA in investigations, inspections, and reporting of potential issues. Short of state-specific compounding data, the federal FDA actions by state may be the best available information.

\section{How Can We Measure Pharmacy Regulatory Burden in States?} Overall regulatory burden is often measured in volume. Researchers routinely note the number of pages of regulations published in the Federal Register annually and measure regulatory reform efforts based on the annual change. ${ }^{21-22}$ More recently, economists at George Mason University have measured regulatory burden based on total regulatory word count and the total number of restrictive words in a state's administrative code..$^{23-24}$ Economist James Broughel has defined restrictive words as "shall," "must," "may not," "prohibited," and "required." ${ }^{23}$ The Mercatus Center publishes a state-bystate comparison of restrictions across all state agencies into a single state summary measure. ${ }^{24}$

While simplistic, this approach provides an easy starting point for establishing a baseline measure of pharmacy regulatory burden. Researchers simply need to assemble the relevant pharmacy statutes and regulations, copy them into Microsoft Word, and use the 'Word Count' tool to quantify total work count, and the "search in document" function to find and quantify the number of restrictions. This approach was recently used to generate cross-state comparisons of pharmacy regulations in 10 western states. ${ }^{3}$

Some may note that quantity alone is insufficient and that we should also look at the quality of the regulation; while hard to disagree with in principle, we are not aware of a consensus definition of quality in pharmacy regulation that yet exists. Further, to the extent quality is measured, it should likely be linked to public safety outcomes and the current ability to measure these is limited as previously described.

\section{Should We Expect Significant Differences in Public Safety Outcomes Between States Based on Pharmacy Regulation?}

States are often described as the "laboratories of democracy," and states have taken many different approaches to regulating the practice of pharmacy. ${ }^{25}$ As such, differences in pharmacy regulation between states could provide a natural experiment to assess the public safety outcomes that result from different regulatory approaches. While this is conceivable, a variety of factors make it unlikely there are significant differences in pharmacy outcomes across state lines.
For example, the entry-level credentials for pharmacists in the United States have generally been standardized. All pharmacists must graduate from a doctoral program that meets private accreditation standards from the Accreditation Council for Pharmacy Education (ACPE). ${ }^{26}$ Further, all graduates must pass a standardized exam (e.g., NAPLEX) prior to entry into practice. ${ }^{27}$ These factors undoubtedly reduce the regional variation in fitness to practice by ensuring minimum competency to practice as a pharmacist.

Further, the vast majority of pharmacists are employees, most commonly at chain pharmacy organizations or health-systems (e.g., hospitals). ${ }^{28}$ These companies are major targets of litigation and, as such, adopt risk mitigation strategies to lower their corporate legal and financial risk. Companies adopt risk mitigation strategies even in the absence of law; for example, many states allow pharmacists to immunize patients of any age, while some corporations still limit vaccinations to patients above the age of nine because of the perceived risk of vaccinating younger patients. ${ }^{29}$

Similarly, corporations invest in technology systems that have engineered out many legal issues of the past. In prior years, pharmacists had to rely on memory of how many refills are allowable in certain cases or what must be on a prescription label. Pharmacy computer systems now prevent filling a prescription outside of these legal boundaries. ${ }^{30}$ Since many of these chain pharmacy organizations and health-systems operate across state lines, this likely serves to lower regional variation.

Further, federal laws are still applicable to state-licensed pharmacies. Pharmacies must follow the federal Controlled Substances Act overseen by the Drug Enforcement Administration, compounding laws overseen by the FDA, and other federal laws related to patient privacy protections and even patient counseling. ${ }^{31-32}$ Thus, there is a common framework for regulating pharmacy that applies to all states through these federal laws. A variety of factors thus regulate a market, not just state laws: federal laws, facility policies, payer policies, accreditation standards, professional ethics, threat of liability and even norms. ${ }^{33-34}$

As an exploratory approach we used each of the aforementioned dependent variables with available statespecific information, calculated the Pearson (R) correlation coefficient with the volume of regulation reported for 10 western states, and calculated a p-value with a significance level of 0.05 to determine statistical significance. Three measurers reached a level of statistical significance: FDA Actions increased as regulatory burden increased $(R=0.640$; $p=0.046)$; opioid grams per capita $(R=0.770 ; p=0.009)$ and pharmacy robberies/burglaries per capita $(R=0.867 ; p=0.001)$ also increased as regulatory burden increased. This is not to suggest that we believe increased regulatory volume led to worse outcomes; there is likely randomness to each of these. 
Instead, we note that we did not find evidence to suggest states with lower regulatory volume have worse outcomes with these specific measures in these specific states and that much more work is necessary to measure pharmacy outcomes at the state level.

\section{Striking the Balance: How to Regulate to Achieve Optimal Public Safety Outcomes}

In thinking through how to regulate, boards of pharmacy should consider two major points previously raised: 1) many market forces work in combination with state regulation to ensure public safety outcomes; and 2) formal disciplinary actions against pharmacy licensees are very infrequent. Thus, it seems preferable for states to have a regulatory framework that allows boards of pharmacy to deal with the rare public safety issues that occur, while not holding back the vast majority of pharmacists from practicing to the top of their education and training.

One way to accomplish this is to pursue a "standard of care" regulatory approach. A regulatory model based on the "standard of care" is more flexible and is determined by the individual circumstances that present in practice rather than specific requirements codified in law. ${ }^{36}$ It does so by focusing on "that which a minimally competent physician in the same field would do under similar circumstances," providing a board a mechanism to consider individual circumstances as opposed to trying to anticipate and prevent every situation in advance. ${ }^{35}$ Thus, rather than having overly-prescriptive regulations that may not anticipate future practice changes, a "standard of care" approach naturally supports practice evolution while allowing the regulatory boards to pursue discipline against the typical 0.47 to $0.55 \%$ of pharmacists who are found to violate the "standard of care" in practice. This is generally the regulatory model used in the medical profession.

Regulations beyond that which are necessary may not contribute to better public safety outcomes and may instead hold back the profession from achieving optimal public safety outcomes. For example, regulations that prohibited pharmacists from administering vaccines prevented a service that has since been proven safe and effective and has increased vaccine rates by leveraging the convenience and accessibility of pharmacists. $^{37-38}$ Similarly, regulations that prevent pharmacists from treating minor ailments, such as influenza, uncomplicated urinary tract infections, and Group A Streptococcus are limiting public access to an evidence-based service that has been shown to improve antimicrobial stewardship. $^{39-42}$ Regulations that prevent pharmacy technicians from performing drug product verification may actually result in more medication errors. ${ }^{43}$

Excess regulations have also created a confusing patchwork of state laws that even regulatory boards have a hard time keeping track of. For instance, 23 state boards of pharmacy recently said that pharmacists may not administer tests in their state; this was likely a surprise to the 4,107 pharmacies already holding proper credentials to administer tests in those same states. ${ }^{44}$ When boards are unable to accurately advise licensees on what is allowable in practice, this is highly suggestive of a regulatory environment that is not effectively serving the public.

Given that existing data resources related to safety outcomes are suboptimal, states with high levels of regulation should work to validate the necessity of their regulations and document the public safety outcomes achieved relative to other states with lower regulatory burdens. This work, if done well, would provide a framework for regulatory burden analysis to support evidence-based policymaking. Until then, as a default, policymakers should err on the side of less regulation unless compelling evidence justifies a more heavy-handed approach. Regulatory boards can strike a balance by ensuring they have a framework to pursue discipline against the rare bad actors while not discouraging innovation that can improve public safety.

\section{References}

1. Cacciatore GG. The overregulation of pharmacy practice. Pharmacotherapy. 1997;17(2):395-396.

2. Adams, A.J. Transitioning Pharmacy to "Standard of Care" Regulation: Analyzing how Pharmacy Regulates Relative to Medicine and Nursing. Res. Soc. Adm. Pharm. 2018, 15, 1230-1235, doi:10.1016/j.sapharm.2018.10.008.

3. Adams, AJ. Regulating Pharmacy Practice: Analysis of Pharmacy Laws in Ten States. Innovations in Pharmacy. 2020;11(4):20. DOI: https://doi.org/10.24926/iip.v11i4.3344

4. National Association of Boards of Pharmacy. 2018 Survey of Pharmacy Law. January 2018. Chicago, IL.

5. National Association of Boards of Pharmacy. 2020 Survey of Pharmacy Law. January 2020. Chicago, IL. Available from: https://nabp.pharmacy/publicationsreports/publications/survey-of-pharmacy-law/ (Accessed August 15, 2020)

6. National Association of Boards of Pharmacy. 2019 NABP Clearinghouse Totals Announced. Innovations. April 2020;49(4):13-14. Available from: https://nabp.pharmacy/wpcontent/uploads/2020/04/Innovations-Newsletter-April2020.pdf (Accessed August 15, 2020)

7. National Practitioner Data Bank (NPDB). Data Analysis Tool. Available from: https://www.npdb.hrsa.gov/analysistool/ (Accessed August 15, 2020)

8. National Practitioner Data Bank (NPDB). Public Use Data File. Available from: https://www.npdb.hrsa.gov/resources/publicData.jsp (Accessed August 15, 2020)

9. Degnan DD, Hertig JB, Peters MJ, Stevenson JG. Board of Pharmacy Practices Related to Medication Errors and Their Potential Impact on Patient Safety. Journal of Pharmacy Practice. 2018;31(3):312-321. DOI: 10.1177/089719007715562 
10. Boysen PG. Just Culture: A Foundation for Balanced Accountability and Patient Safety. Oschner J. 2013;13(3):400-406.

11. Simko M, Stillings WJ. Discipline Sanctions for Dispensing Errors: Impediment or Aid to Patient Safety. Preseneted at American Society for Pharmacy Law, Developments in Pharmacy Law Seminar. November 5, 2017. Scottsdale, AZ

12. Pharmacy Quality Alliance (PQA). PQA Measure Use in CMS' Part D Quality Programs. Medicare Part D Star Ratings. Available from: https://www.pqaalliance.org/medicarepart-d (Accessed August 15, 2020)

13. Centers for Disease Control and Prevention (CDC). U.S. Opioid Prescribing Rates, 2018. Available from: https://www.cdc.gov/drugoverdose/maps/rxcounty2018.ht $\underline{\mathrm{ml}}$ (Accessed August 15, 2020)

14. Soh C, Brantley K. Opioid Supply Levels Decline in Most States. Avalere Health. June 19, 2018. Available from: http://avalere.com/expertise/life-sciences/insights/opioidsupply-levels-decline-in-most-states (Accessed August 15, 2020)

15. Centers for Disease Control and Prevention (CDC). Drug Overdose Death Data. Available from: https://www.cdc.gov/drugoverdose/data/statedeaths.html (Accessed August 15, 2020)

16. U.S. Drug Enforcement Administration. Federal Burglary Reports of Controlled Substances: Calendar Year 2018. Available from: https://www.deadiversion.usdoj.gov/21cfr reports/theft/ maps/DTL Burglary By State CY2018.pdf (Accessed August 15, 2020)

17. U.S. Drug Enforcement Administration. Federal Armed Robbery Reports of Controlled Substances: Calendar Year 2018. Available from:

https://www.deadiversion.usdoj.gov/21cfr reports/theft/ maps/DTL Armed Robbery By State CY2018.pdf (Accessed August 15, 2020)

18. National Association of Chain Drug Stores. Chain Member Fact Book. 2017-2018. Arlington, VA.

19. Centers for Disease Control and Prevention. Multistate Outbreak of Fungal Meningitis and Other Infections. Available from: https://www.cdc.gov/hai/outbreaks/meningitis.html (Accessed November 8, 2020)

20. U.S. Food \& Drug Administration. Compounding: Inspections, Recalls, and other Actions. Available from: https://www.fda.gov/drugs/guidancecomplianceregulatoryi nformation/pharmacycompounding/ucm339771.htm (Accessed August 15, 2020)

21. Davies A, de Rugy V. Midnight Regulations: An Update. Mercatus Working Papers. March 2008. Available from: https://www.mercatus.org/system/files/WP0806 RSP Mid night Regulations.pdf (Accessed August 15, 2020)

22. Crews CW. Trump Regulations: Federal Register Page Count is Lowest in Quarter Century. Competitve Enterprise Institute. December 29, 2017. Available from: https://cei.org/blog/trump-regulations-federal-registerpage-count-lowest-quarter-century (Accessed August 15, 2020)

23. Broughel J. A Step-by-Step Guide to Using Mercatus Tools to Reduce State Regulation Levels. Mercatus Policv Briefs. April 11, 2017. Available from: https://www.mercatus.org/system/files/broughel-regdatastate-guide-mop-v1.pdf (Accessed August 15, 2020)
24. Broughel J, Ampaabeng K. A Snapshot of Regulation in Southern US States. Mercatus Policy Briefs. June 8, 2020. Available from:

https://www.mercatus.org/system/files/broughel and am paabeng - policy brief -

a regional snapshot of southern us regulation v1.pdf (Accessed August 15, 2020)

25. Blakeman BA. States are the laboratories of democracy. The Hill. May 7, 2020. Available from:

https://thehill.com/opinion/judiciary/496524-states-arethe-laboratories-of-democracy (Accessed August 15, 2020)

26. Accreditation Council for Pharmacy Education. Accreditation Standards and Key Elements for the Professional Program in Pharmacy Leading to the Doctor of Pharmacy Degree. February 2, 2015. Available from: https://www.acpeaccredit.org/pdf/Standards2016FINAL.pdf (Accessed August 15, 2020)

27. National Association of Boards of Pharmacy. NAPLEX/MPJE 2020 Candidate Application Bulletin. July 2020. Available

from: https://nabp.pharmacy/wpcontent/uploads/2019/03/NAPLEX-MPJEBulletin July 2020.pdf (Accessed August 15, 2020)

28. Arya V, Bakken BK, Doucetter WR, et al. National Pharmacist Workforce Study 2019. Available from: https://www.aacp.org/sites/default/files/202003/2019 NPWS Final Report.pdf (Accessed August 15, 2020)

29. Rosenfeld LA., Etkind P, Grasso A, et al. Extending the reach: local health department collaboration with community pharmacies in Palm Beach County, Florida for H1N1 influenza pandemic response. J Public Health Manag Pract 2011;17:439-448.

30. Adams AJ. Toward Multistate Pharmacy Practice: Enhancing Mobility and Portability of Pharmacist Licensure. Annals of Pharmacotherapy. 2020.

https://doi.org/10.1177/1060028020945254

31. Drug Enforcement Administration. Pharmacist's Manual. An Informational Outline of the Controlled Substances Act. 2010. Available from:

http://boards.bsd.dli.mt.gov/Portals/133/Documents/pha1 /dli-bsd-pha040.pdf (Accessed August 15, 2020)

32. U.S. Food and Drug Administration. Human Drug Compounding. Available from:

https://www.fda.gov/drugs/guidance-complianceregulatory-information/human-drug-compounding (Accessed August 15, 2020)

33. Safriet BJ. Closing the Gap Between Can and May in HealthCare Providers' Scope of Practice: A Primer for Policymakers. Faculty Scholarship Series. Yale Journal of Regulation 301. 2002. Available from: http://digitalcommons.law.yale.edu/fss_papers/4422 (Accessed August 15, 2020)

34. Thierer A. Permissionless Innovation: The Continuing Case for Comprehensive Technological Freedom. March 15, 2016. Available from:

https://www.mercatus.org/system/files/ThiererPermissionless-revised.pdf (Accessed August 15, 2020)

35. Moffett P, Moore G. The Standard of Care: Legal History and Definitions: the Bad and Good News. West J Emerg Med. 2011 Feb;12(1):109-112. 
36. Adams AJ. Pharmacist Prescriptive Authority: Lessons from Idaho. Pharmacy. 2020;8:112. Doi:

10.3390/pharmacy8030112

37. Otsuka S, Tayal NH, Porter K, et al. Improving Herpes Zoster Vaccination Rates Through Use of a Clinical Pharmacist and a Personal Health Record. American Journal of Medicine. September 2013;832.

38. Taitel M, Cohen E, Terranova B, et al. Pharmacists as Immunization Providers: Patient Attitudes and Perceptions. Pharmacy Times. Available from: http://www.pharmacytimes.com/publications/issue/2011/ September2011/Pharmacists-as-Immunization-ProvidersPatient-Attitudes-and-Perceptions/ (Accessed August 15, 2020)

39. Klepser ME, Adams AJ, Klepser DG. Antimicrobial stewardship in outpatient settings: Leveraging innovative physician-pharmacist collaborations to reduce antibiotic resistance. Health Secur. 2015, 166-173, doi:10.1089/hs.2014.0083.

40. Klepser DG, Klepser ME, Smith JK, et al. Utilization of influenza and streptococcal pharyngitis point-of-care testing in the community pharmacy practice setting. Res. Soc. Adm. Pharm. 2018, 14, 356-359, doi:10.1016/j.sapharm.2017.04.012.

41. Beahm NP, Smyth DJ, Tsuyuki RT. Outcomes of Urinary Tract Infection Management by Pharmacists (RxOUTMAP): A study of pharmacist prescribing and care in patients with uncomplicated urinary tract infections in the community. Can. Pharm. J. 2018, 151, 305-314.

42. Akers JM, Adams AJ, Klepser ME. Review of PharmacyBased Management of Uncomplicated Urinary Tract Infections (UTIs) in Community Pharmacy Settings. Int J Pharm 2018;8(2):63-69. Available online: http://pharmascholars.com/abstractview/review-ofpharmacy-based-management-of-uncomplicated-urinarytract-infections-utis-in-community-pharmacy-settings (accessed on 2 June, 2020).

43. Adams AJ, Martin SJ, Stolpe SF. "Tech-check-tech": A review of the evidence on its safety and benefits. Am J Health-Syst Pharm. 2011; 68:1824-33.

44. Klepser ME, Adams AJ, Klepser DG. Clinical service implementation in the face of initial regulatory uncertainty. J Am Pharm Assoc. 56(2016):492. 